\title{
The economic value of the enterprise for stakeholders in the fuel and energy sector
}

\author{
Sylwia Lorenc ${ }^{1, *}$ \\ ${ }^{1}$ AGH University of Science and Technology, Department of Economy and Management in Industry, \\ al. Mickiewicza 30, 30-059 Krakow, Poland
}

\begin{abstract}
The purpose of this article is to present certain trends in the distribution of value created by businesses for groups of stakeholders as part of a conception of sustainable growth. The subject of this analysis is the LW Bogdanka S.A. mining company, which was studied in terms of distribution of value for the period from 2009 to 2015. In this paper, the main stakeholders of the operation were identified as the shareholders, capital providers, employees, suppliers, local governments and the state. A method for measuring distributed value based on cash flow is demonstrated. Identification of the value added by the proposed methodology may assist of decisions related to the continuation or liquidation of operations.
\end{abstract}

\section{Introduction}

The primary aim of every business is to maximise its value in the long term. This effort to increase the business' value is inextricably linked with the attempt to answer the questions of what category of value is under consideration, for whom is this value meant to be created, and what methods are to be used in order to create it. Until recently, all models, methods, and tools used for assessment were based on an estimation of the value created for owners. Currently, as the aims and strategies of businesses are undergoing reorientation towards the creation of sustainable businesses, this value is increasingly coming to be understood as that created for all groups of stakeholders, including clients, employees, investors, and the immediate and further environment. As a result, modern business management practices involve the necessity to take a multi-dimensional approach to the value of the business, and to its fundamental role in creating mutual relations between the business and its environment. We can speak then of a bundle of aims which determines the common coordination of the interests of all groups of stakeholders in their effort to achieve economic, social, production and marketing, and environmental aims in order to meet the expectations of and deliver benefits to all the groups involved. In the case of fuel and energy businesses who depend on mutual relations with their surroundings, the building of sustainable value which meets the needs of all groups of stakeholders is essential.

The purpose of this article is to present current trends in the distribution of value generated by the business for its stakeholders, in accordance with the assumptions of sustainable growth. For the purposes of defining value for the individual groups of stakeholders in this

\footnotetext{
* Corresponding author: slorenc@agh.edu.pl
} 
article, a research method using dynamic accounting based on free cash flow founded on value added has been used. The subject of this analysis is the LWB S.A. mining company.

\section{Pricing model of company's sustainable value}

The problem of assessing value for the owners of the business is relatively easy to solve by using common assessment methods such as EVA (economic value added), MVA (market value added), TSR (total shareholder return) and others [1]. However, in what way should value be assessed for other groups of stakeholders? The identification and measurement of this value is a critical task for sustainable businesses. The development of an appropriate calculation model for all interested parties would be of great aid in solving this problem.

In our era of social and economic change, in which the stakeholders' need for information is constantly rising, it would seem essential not only to assess value, but above all to develop an efficient and transparent system for reporting the value created and the system of distribution of this value. It is after all on the basis of the quality and type of information presented that the various interest groups make their own assessments.

The distribution policy for the value created requires the definition of its structure. This structure illustrates the proportional distribution of value generated to the various groups of beneficiaries. In this paper, the distribution process for this value is presented based on the well-known concept of value added as it is earmarked for distribution among the various beneficiaries in the form of remuneration, interest, dividends, retained profits, and taxes [2]. However, methods of assessing value added which are well-known in the literature and in business make use of accrual accounting based on net profit, which supplies an insufficiently broad spectrum of information and is subject to numerous distortions [2, 3]. To eliminate the flaws of this method, the author of this paper decided to make use of a dynamic method of assessment of sustainable value, based on cash flows which have been used to present value generated in previous periods. These dynamic methods, based on DCF (discounted cash flow) would seem to be a more reliable tool for measurement than static tools. Income approaches compare the value of a business to its ability to generate income streams in the future, in accordance with the maxim that a business is worth as much as can be earned on it. Dynamic methods allow the structure of value distribution to be defined and give a realistic reflection of the financial benefits which are received by individual groups of beneficiaries. These benefits most often can be expressed in financial categories defined by cash flows. For the purposes of this analysis, two approaches to valuation have been used [4]:

\section{- FCFF (free cash flow to firm)}

- FCFE (free cash flow to equity)

The concept of valuation based on FCF (free cash flow) is based on the use of cash flows from operations, not accounting for liabilities, after taxation. A model based on FCFF permits the assessment of the total value of the business (equity $E+$ debt D) for all parties which finance the operations (owners and lenders) [4]. FCFE permits the calculation of potential equity which is available to the owners.

The proposal to make use of cash flow makes it necessary to introduce the concept of FCF VA (free cash flow from value added). This is the sum of cash flow to various groups of beneficiaries, including owners FCFE (free cash flow to equity), employees FCFW (free cash flow to workers), providers of capital FCFD (free cash flow to debts), suppliers FCFS (free cash flow to suppliers), municipal administration FCFM (free cash flow to municipal administration) and the state FCFSt (free cash flow to state).

For the groups presented, the value distributed throughout the business takes the form of benefits from cash inflows, which for the company become an expense related to costs. For this reason, free cash flow for owners has been estimated as a derivative of profit, depreciation, investment expenses, demand for net working capital, and capital instalments. 
Cash flow for banks are the result of paying interest and capital instalments. Cash flow for employees are a consequence of salaries, wages, and other social security benefits. Free cash flow for suppliers is the result of costs borne for materials, energy, and external services contracted for the benefit of the company. Cash flow for municipal administration and the state are a derivative of taxes and fees paid, as well as of income tax. The methodology accepted in this paper based on records of costs categorised by type in the operations sector is justified in the case of assessment of value added for all stakeholders by the need for a wider view on the aggregate costs of the operation of economic entities. Excessively generalised treatment of costs in this respect may result in incomplete information regarding the creation of real value for the interest groups [5].

\section{Distribution of value added on the example LWB S.A.}

The subject of this analysis is LWB S.A, a mining company which extracts coal in the Lublin Basin. The company is one of the leaders of the coal industry in Poland, exceptional due to its financial results, the efficiency of its extraction operations, and its investment plans for the development of new deposits [6]. LWB S.A. has an active policy regarding sustainable development including an implemented social responsibility strategy. LWB S.A reports the results of this sustainable development by means of CSR reports and integrated reports. Thanks to this, the company has been able to build a positive public image, creating value for shareholders and stakeholders alike. For these reasons, LWB S.A. would seem to be a benchmark in terms of best practice and constitutes a starting point for this analysis. The research methods, which combined accrual and cash flow accounting techniques, permit an analysis of the distribution of value created in the company between 2009 and 2015, from the company's IPO to the latest current data from financial reports.

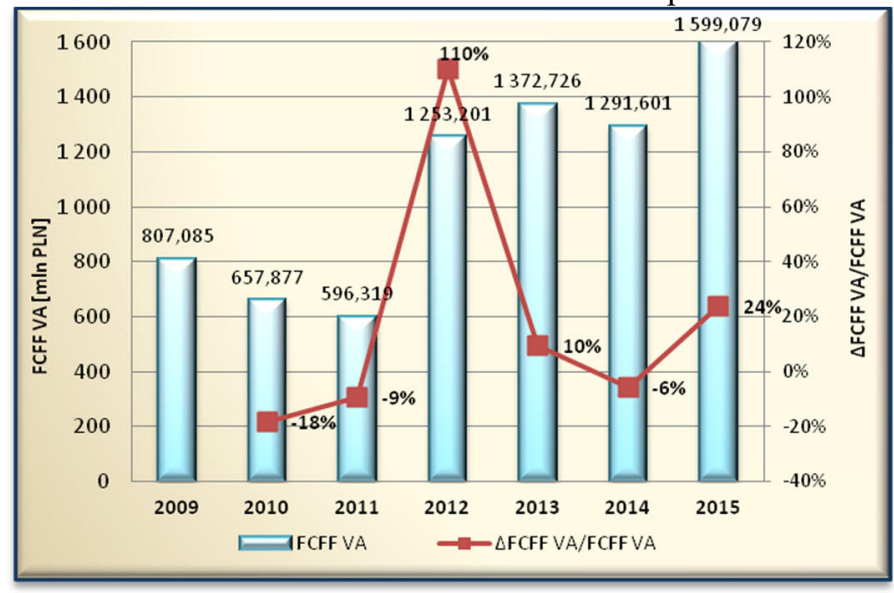

Fig. 1. Free cash flow from value added for all stakeholders generated by LWB S.A. in 2009-2015. Based on company data [7].

The benefits generated by the company which were estimated and are presented here have been assigned to individual groups of stakeholders. For specific years under study, the amounts are presented which reach different beneficiaries including shareholders, investors, employees, suppliers, local authorities, and the state. By using appropriate methodologies amounts of free cash flow have been calculated and analysed for each of these groups: free cash flow to equity, free cash flow to debts, cash flow based on costs by nature - free cash flow to workers, suppliers and municipal administration and free cash flow to state, in other words, income tax. The starting point for the analysis was to define FCFF VA- the total value 
generated by LWB S.A. for its stakeholders in the years 2009-2015. The analysis was supplemented with an illustration of the dynamics of change, as shown in Fig. 1.

Fig. 1 illustrates the differentiated growth of value for specific periods. A drop in gross profits took place in the years 2009-2010 (18\%), 2010-2011 (9\%) and 2013-2014 (6\%). The most dynamic change can be noted in the years 2011-2012 (growth of 110\%) and 2014-2015 (growth of $24 \%$ ). This greater than double increase in value (110\%) was brought about by a change in the cash flow for owners (negative FCFE in 2011, followed by positive in 2012), and in turn a $24 \%$ increase by a change in cash flow for financing institutions FCFD).

In 2009-2015 total value added based on the cash flows which was generated by LWB S.A. for its stakeholders amounted 7577888004 PLN. Tab. 1 and Fig. 2 show the way and proportions of distribution value for different stakeholders.

Table 1. The value added based on the cash flows generated by LWB S.A. for stakeholders in 20092015 [mln PLN]. Based on company data [7].

\begin{tabular}{cccccccc}
\hline & $\mathbf{2 0 0 9}$ & $\mathbf{2 0 1 0}$ & $\mathbf{2 0 1 1}$ & $\mathbf{2 0 1 2}$ & $\mathbf{2 0 1 3}$ & $\mathbf{2 0 1 4}$ & $\mathbf{2 0 1 5}$ \\
\hline FCFE & 149,478 & $-209,558$ & $-321,662$ & 173,015 & 262,024 & 187,537 & 188,135 \\
\hline FCFD & $-154,925$ & $-28,108$ & $-120,679$ & $-151,191$ & $-198,137$ & $-247,827$ & 170,506 \\
\hline FCFW & 324,755 & 317,409 & 344,950 & 403,055 & 435,376 & 484,242 & 473,271 \\
\hline FCFS & 423,501 & 501,561 & 623,159 & 728,741 & 762,165 & 764,438 & 673,879 \\
\hline FCFM & 17,281 & 18,465 & 19,815 & 26,527 & 27,297 & 29,709 & 29,863 \\
\hline FCFSt & 46,993 & 58,107 & 50,735 & 73,055 & 84,001 & 73,502 & 63,423 \\
\hline $\begin{array}{c}\text { FCFF } \\
\text { VA }\end{array}$ & 807,085 & 657,877 & 596,319 & 1253,201 & 1372,726 & 1291,601 & 1599,079 \\
& & & & & & SUM of & $\mathbf{7 5 7 7 , 8 8 8}$ \\
\hline
\end{tabular}

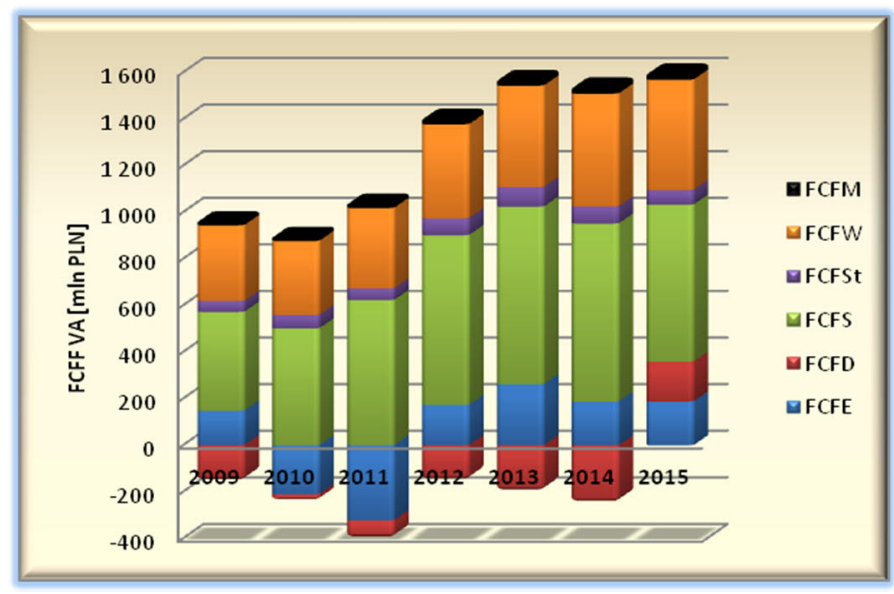

Fig. 2. Proportions of distribution value for different stakeholders in 2009-2015. Based on company data [7].

The largest share in the value generated by LWB S.A. is enjoyed by suppliers (59.1\%). These noted especially high values in the year 2014, when the value created for this group totalled more than 764 million PLN. In the case of suppliers, there has been a general growth trend in share of value, with the exception of 2015 , when a drop in value of $12 \%$ took place. 
The second largest share in total value is enjoyed by employees (36.7\%). For this group, as for the previous one, a steady increase in value with a slight drop in the last year $(2 \%)$ can be observed in the period analysed.

Free cash flows for banks in the majority of years analysed were negative values. These negative values for this group indicate that in the years 2009-2014, capital instalments were negative in spite of positive interests. This fact results from the cash flow approach. In those years banks have not benefited from the mutual relations with the company.

The share of the state budget in the years analysed is in the area of 4-9\%. In 2015, the taxes paid by the company to the state budget were the lowest to date in comparison with preceding years. The average mandatory tax burden which the company paid to the state treasury based on the mining operations of LWB S.A. hovers around 64 million PLN annually.

An interesting situation can be seen in the case of the owners, whose share in the consumption of value is highly differentiated. Their negative share in the distribution of value results primarily from high investment costs and from a negative of need for net working capital. Investments in fixed assets froze available cash resources, and thus lowered FCFE, however in the long term these investments are crucial in order to ensure the proper development of the company. Both investment in working capital and in fixed assets are necessary to maintain the current cash flows and to generate future revenues. The last years of the analysis indicate a stabilisation in cash flows, while recording positive values. The share of the owners in the consumption of value for the period 2009-2015 was on average approximately $5.7 \%$, totalling around 61 million PLN annually.

The share of local government remained on average roughly $2-3 \%$. This group is the smallest beneficiary of value. Payments to local governments in the form of taxes and fees paid by the company total roughly 25 million PLN annually.

The development of cash flow patterns for individual groups of stakeholders with an interest in the total value generated by the company between 2009 and 2015 is illustrated in Figs. 38.

The distribution of this value takes place in the following forms: payment of remunerations and benefits for employees, tax payments for local and national governments, interest for capital providers, dividends for owners, and profits for suppliers of goods and services.

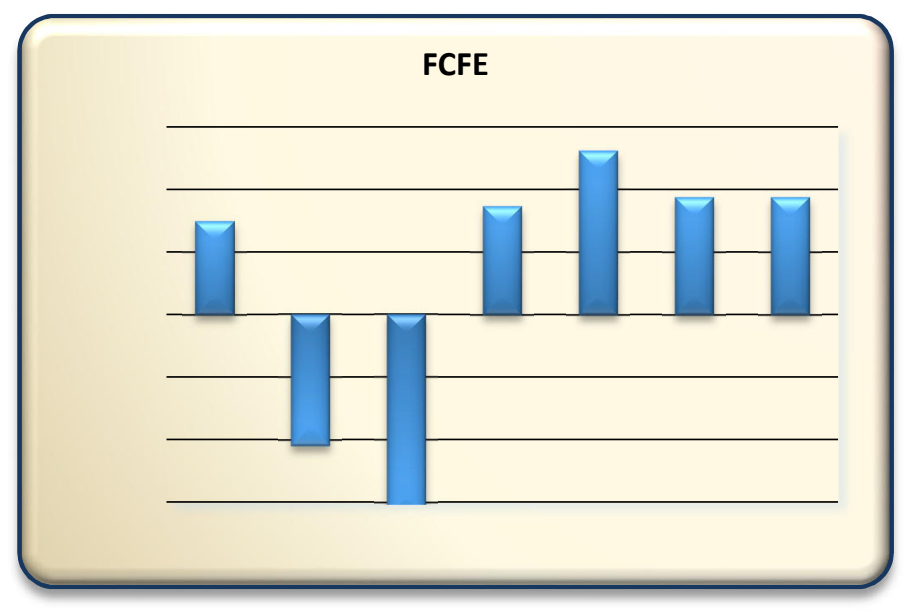

Fig. 3. Free cash flow to equity in 2009-2015 [mln PLN]. Based on company data [7].

The highest value which company has provided to owners can be observed in 2013 in the amount of 262024000 PLN. The lowest value has come at 2010-2011. The worst year for the owners in terms of the benefits they could receive was the year 2011. The lowest negative 
value equal to - 321662000 PLN demonstrates of the need to provide the required cash for the company.

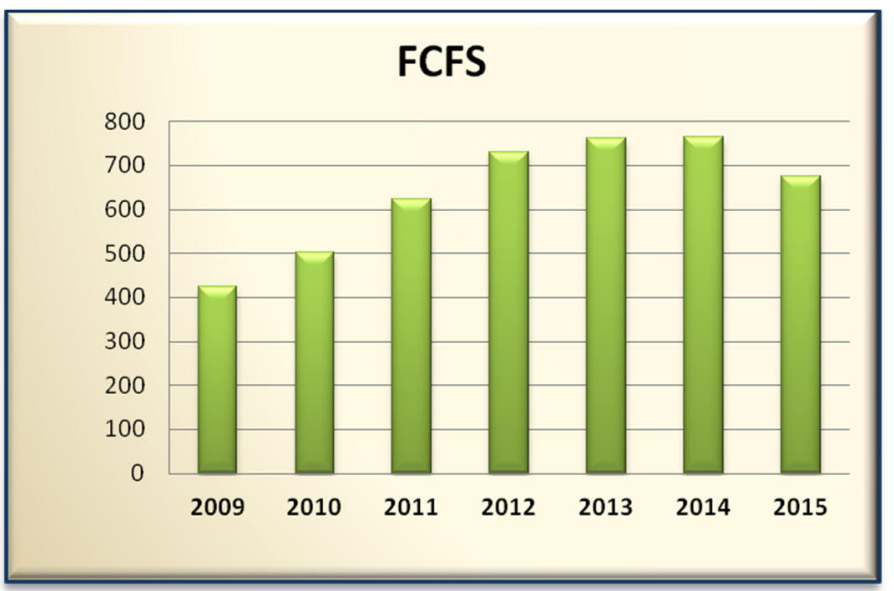

Fig. 4. Free cash flow to suppliers in 2009-2015 [mln PLN]. Based on company data [7].

In the case of suppliers who, according to the analysis, are the main beneficiary of the created value, the biggest gains for them observed in 2014 with amount equal 764438000 PLN. The year 2009 has proven to be the weakest in terms of distributed of benefits, only 423501000 PLN accounted profits for suppliers because of purchase by the LWB S.A. of materials, energy and external services.

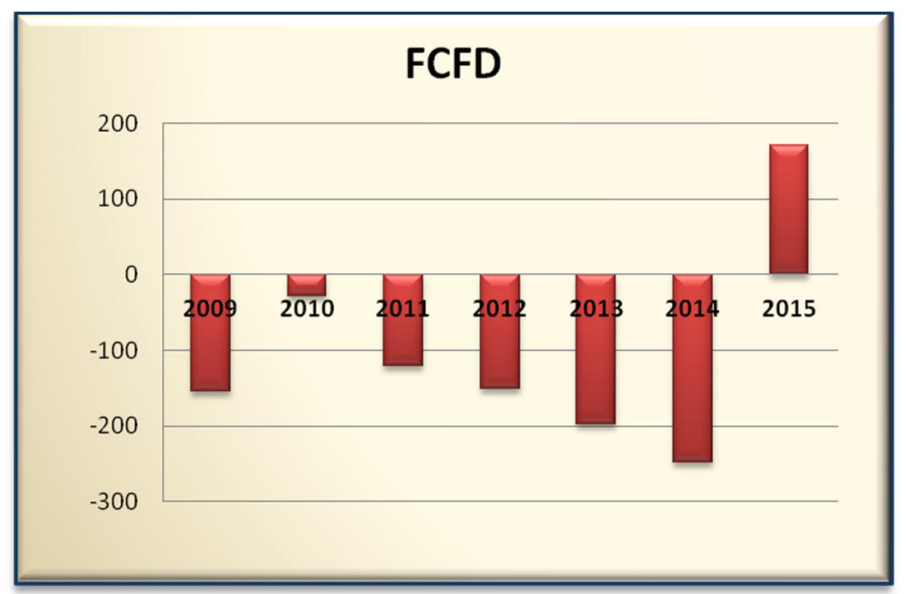

Fig. 5. Free cash flow to debts in 2009-2015[mln PLN]. Based on company data [7].

Providers of capital are the stakeholder, who have gained the least. In 2009-2014 banks have not benefited from relationships with LWB S.A. Only the last 2015 year, has brought a significant improvement in the results for this group of interests generating profits in the amount of 170506000 PLN. 


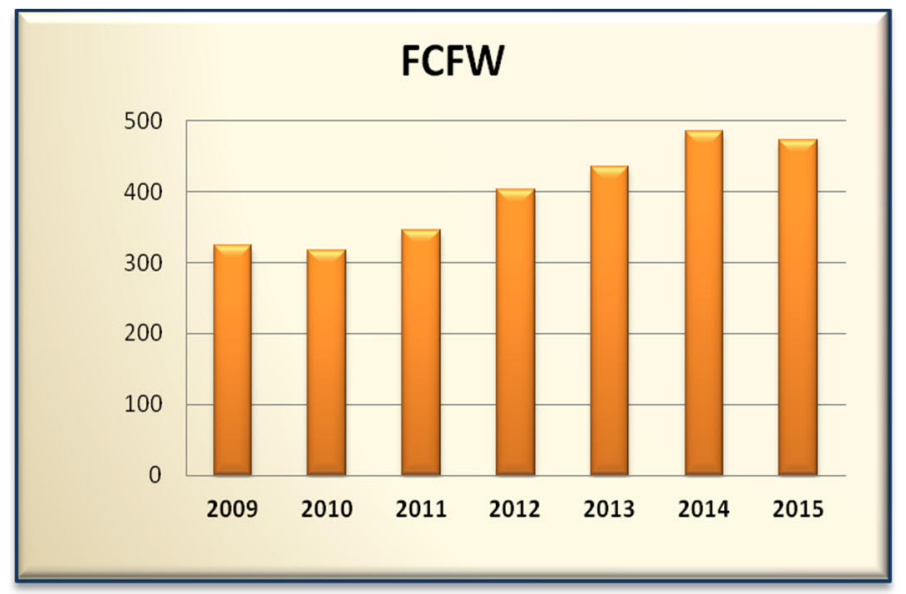

Fig. 6. Free cash flow to workers in 2009-2015 [mln PLN]. Based on company data [7].

For employees, who are the group strongly associated with the company, the highest value generated for them was in 2014 in the amount of 484242000 PLN. The lowest amount of salaries, wages and social security benefits for employees was observed in 2010 in the amount of 317409000 PLN.

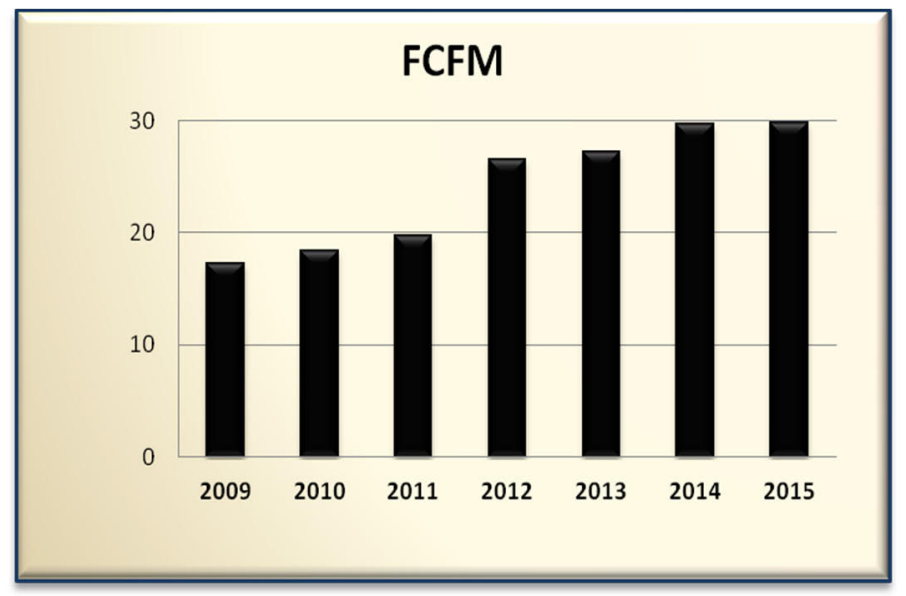

Fig. 7. Free cash flow to municipal administration in 2009-2015[mln PLN]. Based on company data [7].

The lowest value added the company generated for local governments. The highest benefits in the form of taxes and fees which went to this group of interest was recorded in 2015 (29 863000 PLN). The lowest value was observed in 2009 in the amount of 17281000 PLN. 


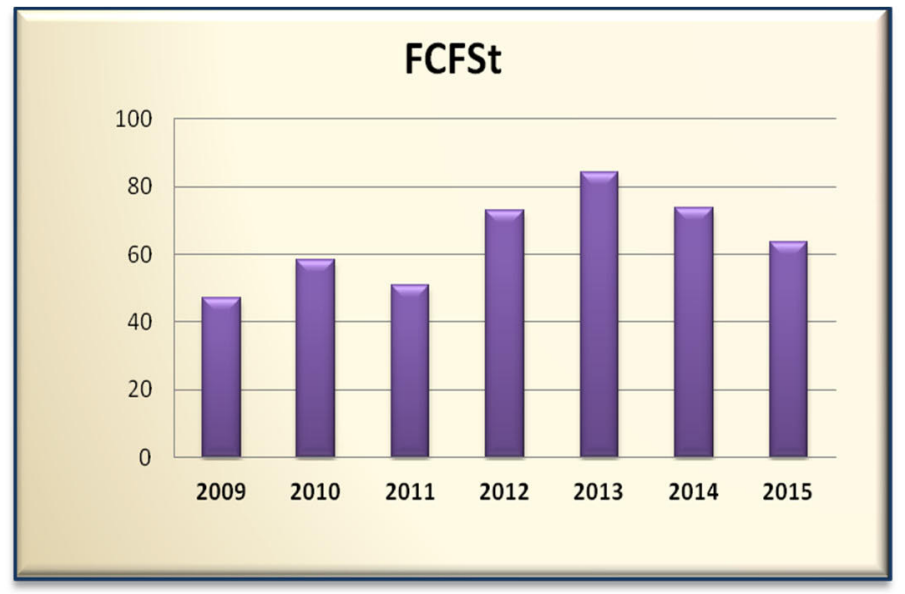

Fig. 8. Free cash flow to state in 2009-2015 [mln PLN].Based on company data [7].

Analysis of distribution of value added in the light of the benefits which goes to the state budget, shows that the highest income LWB S.A. created in 2013 in the amount equal 84001 000 PLN. In turn, the lowest tax which was paid by the company amounted to 46993000 PLN and took place in 2009.

An analysis of charts 2-7 explains the role of LWB S.A. in the creation of private and public incomes, and shows how the operations of the company bring value to the community. Figure 9 shows the percentage of the various interest groups in the total value created in 2009-2015.

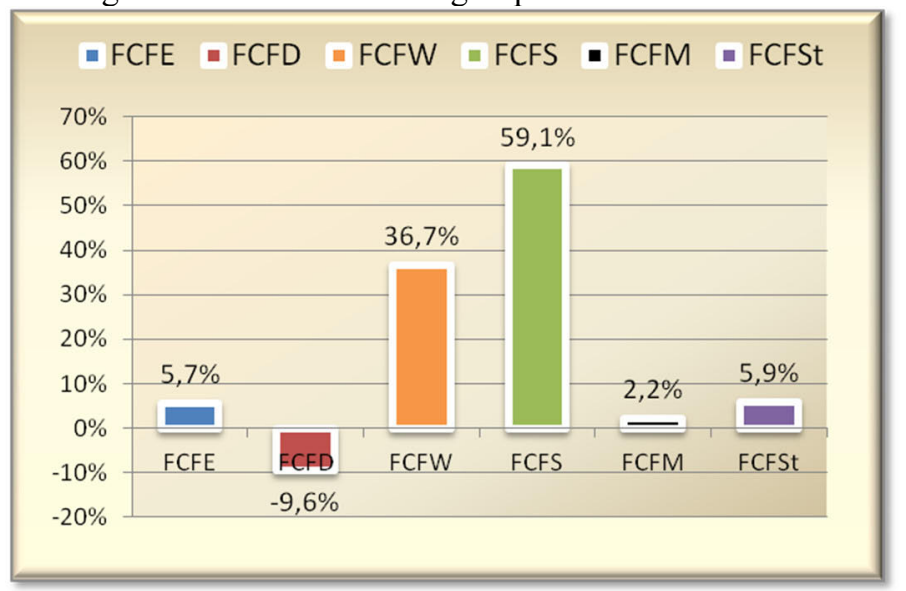

Fig. 9. The percentage of participation of individual stakeholders in the total value added in 20092015.Based on company data [7].

The above figure (9) shows that each of the groups in the analysis has its own larger or smaller share in the consumption of value, benefitting from mutual relations with the company.

The only group which did not participate in the benefits generated by the company in 20092015 are providers of capital. Over the last 7 years (except 2015) banks not only did not profit, it even they had to provide funds for the company (negative value added) (positive interest but negative capital instalments).

Increase on outside capital for the years 2014-2013, 2013-2012, 2012-2011, 2011-2010, 2010-2009 and 2009-2008 suggest that the company took out loans (positive capital instalments for the equity, negative for banks.) Banks obviously benefited from interest, but taking into account the free cash flow approach, capital instalments exceeded the amount of 
interest from here we can observe the negative value for this group of interests. Only in 2015-2014 outside capital has decreased, (banks earned on the relationship with company) suggesting repay financial commitment to banks (negative capital instalments for the equity, a positive for banks), thus the total value of this year for the providers of capital is positive. The presented model emphasises the fact that the value created in the company is a derivative of the joint efforts of the various stakeholders working with the company. The analysis which was conducted shows in what way the effects of these common efforts are distributed among the various groups. The structure of distribution of value of course depends on the financial situation of the company, but not exclusively. In 2015, LWB S.A. recorded a loss, and yet this loss did not prevent the company from meeting the expectations of its stakeholders, for instance by paying salaries, debts and taxes, and by maintaining its suppliers. It is worth noting that despite a momentary lack of profitability, the company still delivered benefits to the community. The implementation of its social policy, based maintaining jobs and supporting local groups linked to the company, increases the trust and loyalty of the clients of the company, which being a publicly traded company must take care to cultivate transparency in its relations with stakeholders, and in doing so create a positive image for the entire energy, mining, and industrial sector.

Thanks to this type of presentation of results, LWB S.A. can accentuate in an accessible way the financial effects of its operations to build positive relations with stakeholders, which in turn influences the emphasis in the company on the implementation of a sustainable growth policy.

\section{Conclusions}

The efficient and transparent communication of a company with its stakeholders should be a priority in running any business whose operations significantly impact parties close to it and the further environment. This is especially true for heavy industries from the fuel and energy sector, for whom finical results cannot be the only indicator of success. The influence of fuel companies on the environment and the community is vast, and the usefulness of the information which is available in published reports is slight. For this reason, there is a need to generate additional information in the form of social reports which would indicate the global impact of a company on the environment and the community, and simultaneously represent an assessment of the value created for these groups. Such a report could include information about the specific value which the industry generates for the national economy in order to illustrate the rational for and usefulness of the operations of these companies.

The failure of contemporary mining and energy companies to generate profits makes it necessary to conduct an analysis accounting for the potential effects which would be felt if these companies were to be liquidated. The analysis conducted for the purposes of this article shows that such effects would be felt not only by the owners, but also by employees, suppliers, financing institutions, the state budget, and other stakeholders.

According to the analysis, the suppliers and employees are the groups who suffer the most in case of termination of activity LWB S.A.. They have the highest share in value which was created by the company. Then, the owners and financial institutions are the groups who suffer the least. The benefits which they receive are incomparably smaller than in the case of employees or suppliers. It is important to note, that employees and suppliers are a group of quantitatively greater than the groups of owners or financial institution. It not without significance is also the question of taxes paid by the company for the state budget and municipal administration. In the face of the present crisis in the mining and energy sector, there are many negative opinions which anchor in the social consciousness. It results mainly from the often false information about pay extra of billion PLN from the state budget to the mining and energy industry. Meanwhile, this analysis shows that it is quite the opposite. The 
mining and energy industry is a powerful payer of all taxes and public law levy. From mining "live" not only municipalities in areas where the mines are located and coal is mined. Without an annual of cash injection from the mining companies, the state budget could have a huge problem. The situation is interesting because this analysis includes only one company which is LWB SA. In this case we can talk about tens of millions of PLN paid to the budget every year but much less in the case of the entire sector.

The presented analysis illustrates to what extent companies in strategic sectors have on their nearer and further environments, as well as on society as a whole. In this area, the presented methodology may assist of strategic decisions related to the continuation or liquidation of operations of mining and energy companies in terms of benefits which these companies provide for stakeholders.

For this reason, strategic decisions on the fate of these companies should be taken based not only on a financial analysis, but also on studies which permit the assessment of the company in terms of the range of benefits that it generates for the community, in accordance with the concept of sustainable development, in order to create a comprehensive and holistic view of the issue.

\section{References}

1. W.Skoczylas, Determinanty i modele wartości przedsiębiorstw, (PWE, Warszawa, 2007)

2. M.F. Morley, The Value Added Statement in Britain, Account Rev, 3 (1979)

3. https://www.isagen.com.co/informe-degestion/2011/archivos/informe_gestion2011_ingles.pdf

4. P. Fernandez, Company valuation methods. The most common errors in valuations, IESEP, 449 (2007)

5. S. Lorenc, A. Kustra, Value added for stakeholders in mining operations based on cash flow, IM, 2 (2016)

6. http://www.lw.com.pl/pl,2,s167,informacje_ogolne.html

7. http://www.ri.lw.com.pl/raporty-okresowe 